\title{
Covid-19 Vaccination and Immunization Barriers in Pakistan
}

\author{
Sana Abbas, Beenish Abbas
}

How to cite this Article:
Abbas S, Abbas B. Covid-19 Vaccination and Immunization Barriers in PakistanJ Bahria Uni Med Dental Coll. 2021; 11(3):140-141
DOI: https://doi.org/10.51985/BFMT6892
This is an Open Access article distributed under the terms of the Creative Commons Attriution Non Commercial Liciense (http:// creativecommons/org/licences/by-nc/4.0)
which permits unrestricted non commercial use, distribution and reproduction in any medium, provided the original work is properly cited.

which permits unrestricted non commercial use, distribution and reproduction in any medium, provided the original work is properly cited.

From January 2020 to May 2021, Pakistan quoted to World health Organization 858,026 confirmed cases and 18,915 deaths of COVID - 19. China donated Pakistan Sinopharm vaccines in February 2021, and the stagewise immunization program started with an enrolment of healthcare workers and the elderly at priority. A total of 2,894,861 vaccine doses have been administered as per statistics of the earlier half of May 2021, which is approximately only 3\% of the total population and target for this year is $30 \% .{ }^{1}$ Several wild conspiracy theories sprouting throughout the community is fuelling the misleading narratives of vulnerable population of Pakistan leading to increased Skeptism against covid-19 vaccine .Of theses alleged claims of religious prohibitions plea that virus was an illusion against Islam to empower Jews and through vaccine nano chips will be inoculated in people to gain control through $5 \mathrm{G}$ towers. ${ }^{2}$

There is an upsurge of several cases and fear of disease due to the ongoing pandemic situation in India. This has forced the government to impose and heighten up virus spread prevention restrictions. The experience of the terrifying situation in India should have alarmed our authorities; they have failed to comply with the seriousness of the issue. Pakistan is on the 29th slot out of 30 countries that have conducted the greatest number of tests per million population (PMP), hence second last on enlistment with 39,136 tests carried out. Israel, United Kingdom and United States secured top 3 ranks with 1,273,050, 1,266,538 and 1,052,930 tests per million populations respectively. Even India has conducted around four times more tests. ${ }^{3}$

Significant vaccine hesitation also has an enormous impact on the control of disease and the emergence of new fatal strains among immunocompromised. Approximately 142,315 healthcare workers were registered in Sindh for Covid - 19 immunization programs, however, 33,356 refused inoculation. To discourage this attitude authority had to take major steps

Sana Abbas
Consultant Anesthetist
GDA Hospital Gwadar
Email: doctor_amcollian@yahoo.com
Beenish Abbas
Assistant Professor, Department of Operative Dentistry I
Foundation University College of Dentistry, Islamabad |
Received: 09-06-2021

of job termination warning. The perspective of front-line warriors of disease who have seen patients dying in their hands and relatives in sheer agony, then the unwillingness of the general population with low literacy is not an unusual revelation. ${ }^{4}$

As evident in the literature by American publication Bloomberg about the global disproportion between the number of vaccines. Pakistan will require about 10 years to immunize $75 \%$ of its population, India would have the option to inoculate a similar level of its populace is around three years. United States, Britain, and Israel were probably going to arrive at the $75 \%$ objective inside a quarter of a year. ${ }^{5}$

Pakistan is already a hub of infectious diseases with epidemics like Tuberculosis and Hepatitis $C$, with the $6^{\text {th }}$ and $2^{\text {nd }}$ highest disease burden globally. The WHO notified, the rate, invasiveness, and mortality of Tuberculosis in Pakistan as 230 per 100000,310 per 100000 , and 39 per 100000 , respectively. This reflects 410000 cases and 69000 deaths of Tuberculosis each year in Pakistan. ${ }^{6}$

Pakistan Polio Eradication Programme (1994) in conjunction with support provided by WHO and UNICEF is determined to eradicate the crippling disease as Pakistan and Afghanistan are only two countries worldwide fighting with menace. In the mid-1990s, the yearly occurrence of polio was assessed at more than 20000 cases every year. So far in 2020, 80 cases have been accounted all over the country from Punjab 13, Sindh 22, Khyber Pakhtunkhwa 22, and Baluchistan 23. ${ }^{7}$ Pandemic of COVID illness 2019 has disrupted immunization programs globally, hence exalting perilous fatal vaccine-preventable diseases. Due to the COVID-19 outbreak vaccination campaigns halted in Pakistan therefore depriving, leading 40 million children of polio vaccination. Deferrals in polio inoculation probably will not have a prompt effect but, in the long haul, the expansion in polio cases in Pakistan could bring about worldwide dissemination of infections. ${ }^{8}$ This is of momentous concern as we have already failed to convince the public to adhere to polio vaccination and disruption in the program can lead to wastage of enormous efforts already contributed towards the program. Additionally, if this scepticism for COVID - 19 vaccinations prevailed we will be stuck into Catch 22 for more epidemics and pandemics.

The advent of Coronavirus disease and vaccination prompted 
Flu vaccination disappearance from the market due to various reasons. Every year on the opinion of epidemiology and health experts to reduce mortality and morbidity high-risk individuals are encouraged to get an influenza vaccination. Two significant distributors are Sanofi and Abbot. Due to boycotts of French products on religious grounds and lack of provision from Abbot due to elevated demands from developed countries Pakistan has failed to procure influenza vaccination hence adding to the dilemma of diseases burden. ${ }^{9}$

A fully immunized child is conceived with at least 1 dose of Bacilli Calmette-Guérin, 3 doses of oral polio, DPT3, and measles 1 vaccination, which ranges from $47 \%-57 \%$ in Pakistan. Child mortality is characterized by $50 \%$ of the country's mortality rate compared with $8 \%$ globally impacted Pakistan due to failure of EPI implementation. However, under five years constitute only $15 \%$ of the total 'country's population ${ }^{10}$ Efforts are in hand to eradicate polio, measles, and neonatal tetanus. Inadequate service delivery, which leads to irregular access and poor service utilization, was the key reason for this poor performance. Recognized issues leading to failure of the Expanded Program of Immunization (EPI) as per various studies conducted on the subject are distant EPI centers, sporadic access to centers, and deficiency of expert staff and services. ${ }^{11}$ These reasons could also be hindrances to the Covid-19 vaccinations program as well.

Authors Contribution:

| Sana Abbas: Conception and Draft

Beenish Abbas: Proofreading and research material

- - - - - - - - - - - - - - -

\section{REFERENCES:}

1. Pakistan: WHO Coronavirus Disease (COVID-19) Dashboard with Vaccination Data | WHO Coronavirus (COVID-19) Dashboard with Vaccination Data. [online] Available at: pk [Accessed 11 May 2021].

2. Khan YH, Mallhi TH, Alotaibi NH, Alzarea AI, Alanazi AS, Tanveer N, et al. Threat of COVID-19 vaccine hesitancy in Pakistan: The need for measures to neutralize misleading narratives. Am J Trop Med Hyg. 2020;103(2):603-4.
3. Mallhi TH, Khan YH, Alotaibi NH, Alzarea AI. Walkthrough sanitization gates for COVID-19: A preventive measure or public health concern? Am J Trop Med Hyg. 2020;103(2):581-2.

4. Puri N, Coomes EA, Haghbayan H, Gunaratne K. Social media and vaccine hesitancy: new updates for the era of COVID-19 and globalized infectious diseases. Hum Vaccines Immunother [Internet]. 2020;16(11):1-8. Available from: https://doi.org/10.1080/21645515.2020.1780846

5. Chandir S, Siddiqi DA, Mehmood M, Setayesh H, Siddique M, Mirza A, et al. Impact of COVID-19 pandemic response on uptake of routine immunizations in Sindh, Pakistan: An analysis of provincial electronic immunization registry data. Vaccine [Internet]. 2020;38(45):7146-55. Available from: https://doi.org/10.1016/j.vaccine. 2020.08.019

6. Qureshi H, Bile KM, Jooma R, Alam SE Afridi HU. Prevalence of hepatitis $\mathrm{B}$ and $\mathrm{C}$ viral infections in Pakistan: findings of a national survey appealing for effective prevention and control measures. East Mediterr Health J. 2010; 16: 15-S23

7. User, S., Pakistan Polio Eradication Programme | end polio Pakistan. [online] Available at: https://www.endpolio.com.pk/ [Accessed 11 May 2021].

8. Din M, Ali H, Khan M.Impact of COVID-19 on polio vaccination in Pakistan: a concise overview. Rev Med Virol. 2020 Nov 11. DOI: 10.1002/rmv.2190. Epub ahead of print. PMID: 33176028.

9. Influenza vaccine not available in Pakistan so far. [online] Available at: https://www.thenews.com.pk/amp/751897influenza-vaccine-not-available-in-pakistan-so-far [Accessed 11 May 2021].

10. Butt M, Mohammed R, Butt E, Butt S, XiangJ. Why Have Immunization Efforts in Pakistan Failed to Achieve Global Standards of Vaccination Uptake and Infectious Disease Control? Risk Manage Health Policy. 2020; 13: 111-124.DOI: 10.2147/RMHP.S211170

11. WHO EMRO $\mid$ A review of EPI progress in Pakistan towards achieving coverage targets: present situation and the way forward | Volume 16, supplement | EMHJ volume 16, 2010. [online] Available at: http://www.emro.who.int/emhj-volume16-2010/volume-16-supplement/article-04.html [Accessed 11 May 2021]. 